\title{
Verification of Promoting Regional Economic Development to the National Sports Base Based on Double Difference Method
}

\author{
ZHANG Qiang, DONG Xiang-rong
}

(Department of Physical Education, Shandong Technology and Business University, Yantai, Shandong, 264005)

Key words: national sports industry base; Regional economic growth; Double difference method

\begin{abstract}
China, has become a new growth point of national economic growth. The establishment of national sports industrial base has contributed to the development of sports industry, but it has yet to be proved whether it has promoted the development of regional economic growth. In this paper, the panel data of 15 regional samples from 2000 to 2015 were adopted, and the influence of the establishment of national sports industrial base on regional economic growth was studied by double difference method. The empirical results show that the construction of the national sports base has significantly promoted the growth of the regional economy, and this conclusion is still valid after the robustness test. Second, national sports industry base on present role in promoting the economic development of the law of "diminishing marginal effect", compared with higher level of the city, a lower level of city from national sports industry base construction of faster growth.The research of this paper shows that the national sports industrial base can not only drive economic development, but also help narrow the gap of economic development between regions through its rational distribution. This provides an important inspiration for the future layout of the national sports industry base and the establishment of other related policies.
\end{abstract}

\section{基于双重差分方法对体育产业基地 推动地区经济增长的验证

\author{
张强＼cjkstart董向荣 \\ （山东工商学院 体育教学部, 山东 烟台 264005)
}

关键词: 国家体育产业基地; 地区经济增长; 双重倍差法

摘 要: 体育产业作为中国最具发展前景的朝阳产业之一，已成为国民经济新的增长点。国家 体育产业基地的设立助推了体育产业的发展，但其是否推动了地区经济的发展还有待验证。 本文采用所选取的 15 个地区样本 2000-2015 年的面板数据, 运用双重倍差法研究了国家体育 产业基地的设立对地区经济增长的影响。实证结果表明：第一，国家体育产业基地的建设显 著地促进了地区经济的增长，这一结论在进行稳健性检验后仍然成立。第二，国家体育产业 基地对经济增长的推动作用呈现“边际效应递减”的规律，相较于较高等级的城市，较低等级 的城市从国家体育产业基地的建设中获得了更快发展。本文的研究表明, 国家体育产业基地 不仅可以驱动经济增长，而且通过对其合理布局，还有助于缩小地区间经济发展差距。这为

作者简介: 张强, 男, 1963.7, 安徽五河人, 教授; 研究方向为体育管理、体育教学。邮箱: zhangqiang1963cn@ 163.com; 电 话：13553135395。董向荣，女，1964.11，山东威海人，副教授；研究方向为体育教学，电话：13589870587。 
国家体育产业基地的未来布局与其他相关政策的设立提供了重要启示。

中图分类号: G803 文献标识码: A 文章编号:

\section{1. 引 言}

当前, 全球体育产业增加值已超过 8000 亿美元，在欧美发达国家，体育产业占国民生产 总值达到 $2 \%$ 左右, 体育产业已经成为国民经济的支柱产业和新的增长点, 但我国体育产业 对 GDP 的贡献却不足 $0.5 \%$ 。十三规划明确提出全面发展体育产业, 提升体育产业的整体发展 水平。自 2006 年开始国家体育总局开始批准建设国家体育产业基地, 国家体育产业基地是国 家为了发展体育产业而建立的综合性国家级平台。由于体育产业作为中国最具发展前景的朝 阳产业之一, 已成为国民经济新的增长点, 因此各地纷纷把体育产业纳入区域经济发展规划 之中，申报国家体育产业基地，依托自身的体育资源发展具有区域特色的体育产业，使体育 产业在地区经济增长中发挥重要的作用，以促进本地区体育产业与经济的协调发展。

然而体育产业基地对经济是否具有推进作用? 对于不同发展程度城市的推动作用如何? 目前还缺少相关的研究，基于此，本文采用双重倍差法，选取六大国家体育产业基地作为对 照组，同时选取具有一定体育产业基础的在 2016 年获批国家体育产业示范基地的其中 9 个城 市作为对照组, 考察国家体育产业基地对地区经济增长的推动作用。同时, 根据人均 $G D P$ 和 城市等级将所选样本划分为发达城市和欠发达城市, 进一步研究国家体育产业基地对不同发 展程度地区经济增长的边际作用。

\section{2. 文献综述}

\section{1 体育产业与经济增长总体依存关系}

纵观国内外, 从上世纪 80 年代开始, 有关体育产业发展对经济増长拉动效应的研究就已 开始出现。例如 Matobartoloci (1997) 就发现, 克罗地亚地区的体育产业发展对经济増长有 明显的促进作用 ${ }^{[1]}$ 。赵聂 (2009) 认为, 随着我国经济的不断发展, 人民生活水平显著提高, 为发展体育经济打造了良好的基础, 当目前经济増长模式不能持续时, 体育产业等新兴产业 将成为经济新的増长点 ${ }^{[2]}$ 。陈文胜 (2012) 通过实证分析认为, 体育产业是经济的绿色增长 点, 也是扩大内需增加居民消费的新生力量 ${ }^{[3]}$ 。薛亮（2017）通过体育产业与经济增长的协 整分析认为体育产业发展能够有效的拉动经济増长 ${ }^{[4]}$ 。

\section{2 国家体育产业基地的设立对体育产业的影响研究}

由于国家体育产业基地是中国特有的一项政策，国外学者对其研究较少，国内学者林向 阳和周红妹（2008）国家产业基地的设立能够更好的整合资源，促进当地体育产业的发展， 发挥产业集聚效应 ${ }^{[5]}$ 。梁强（2013）也认为建设体育产业基地是我国体育产业发展的必由之 路, 能更好促进体育产业的发展 ${ }^{[6]}$, 而邢尊明等（2014）则认为国家体育产业基地亟需规范 管理、系统规划和科学发展，短期对于当地体育产业的发展还难以起到显著作用 ${ }^{[7]}$ 。

\section{3 简评}

总之, 根据已有的研究, 许多学者认为体育产业的发展能够促进当地经济的增长, 而国 家体育产业基地的设立能够促进体育产业的发展。但是, 对于国家体育产业基地的设立对当 地经济影响的研究则比较少见。为此, 本文选用六大产业基地为实验组, 同选用 2016 年新设 立的国家体育产业示范基地为对照组, 运用双重倍差法识别国家体育产业基地的设立对于经 济增长的净效应, 同时对不同秉赋条件的地区影响差异进行研究, 以期得到一些有启发意义 的结论。 


\section{3. 理论分析和模型构建}

\section{1 理论假说}

国家体育产业基地是国家为了发展体育产业而建立的集群式的示范区，体育产业要想成 为支柱产业就必须向规模化的方向发展。各地依托当地的体育资源发展具有区域特色的体育 产业,构建国家级体育产业基地, 目的就是促进本地区地区体育产业协调发展, 使体育产业在地 区经济和社会发展中发挥重要的作用。基于以上分析, 本文提出有待检验的理论假说。

假说 1：国家体育产业基地的建设能够推动地区经济增长。

对于体育产业的发展而言，不同地区的要素禀赋差异会对其产生不同的影响，从而导致 国家体育产业基地的设立对地区经济增长的促进作用不同。根据边际效应递减的基本经济学 原理, 由于更为发达的地区在基础设施、政策优惠方面本身就比相对欠发达地区更为优越, 和产业基地的政策更为接近，因此，同样的政策优惠和资金支持在这些地区更多地扮演了“锦 上添花”的角色，边际效应较小。但是，鉴于欠发达地区的基础设施相对落后、政策壁垒相对 圥繁，因此，国家国家体育产业基地在经济相对欠发达的地区，则更多地属于“雪中送炭”, 对当地经济增长的带动作用和辐射作用更大。

我们将所选的样本分为发达城市和欠发达城市。由于发达城市本身就在要素占有和发 展条件上较为先进, 同样的政策优惠所产生的经济增长促进作用较小, 因此, 我们推想, 国 家体育产业基地的设立对经济增长的边际推动效应会随着城市的禀赋条件呈现递减趋势。据 此, 我们可以提出第二个有待检验的假说。

假说 2: 根据边际效应递减的规律，相对于发达城市，国家体育产业基地对欠发达城市 经济增长的推动作用更大。

\section{2 变量选取}

本文研究的重点是国家体育产业基地的设立对地区经济增长的作用，并对体育产业基地 推动经济增长的地区差异性进行详细分析。除此之外, 考虑到其他经济因素也会影响地区经 济增长, 本文还引入了其他控制变量, 详细的变量设置见表 1 。

(1) 被解释变量。地区经济增长水平 $(G D P)$ 。本文以地区实际人均 $G D P$ 增长率来衡量 地区经济增长水平。我们以 1999 年为基年, 用“地区实际 $G D P$ 除以当年地区年末户籍总人口” 计算得到人均 $G D P$, 再进一步计算其增长率。

(2) 核心解释变量。国家体育产业基地虚拟变量（GTD）。由于本文的数据时段为 2000-2015 年, 因此, 我们根据国家体育总局网站公布的截至 2015 年国务院批准建设的国家 级体育产业基地名单，对各地级市进行赋值。如果某一城市在当年开始设立或已经设立国家 级体育产业基地, 则赋值为 1 , 否则赋值为 0 。

（3）控制变量。政府规模（GOV）。在中国的经济增长中，政府扮演着非常重要的角

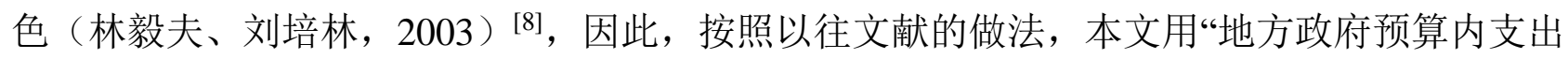
/地区生产总值”计算得到政府支出比重（GOV），用以衡量政府对经济增长的作用。外商直 接投资（FDI）构成了各个地区经济增长的重要源泉, 因此本文通过计算“地区实际利用外商 直接投资/地区国内生产总值”来捕捉外商直接投资水平（FDI）的作用，其中，地区实际利 用外资投资数额的原始数据单位为美元，我们通过各年中间汇率进行了相应换算。地区固定 资产投资 ( FAR ) 是经济增长的重要推动力量, 是拉动经济增长的三架马车之一, 用每年固 定资产投资额来表示。教育水平（ $E D U ）$ 高素质的人力资本对经济增长也具有重要作用（李 国平、范红忠，2003） [9]，本文计算“地区普通高等学校在校生数/地区总人口”来度量高等教 育水平。储蓄率 $(S A V)$ 中国转轨经济的典型特征就是长期持续的高储蓄率（李扬、殷剑锋,

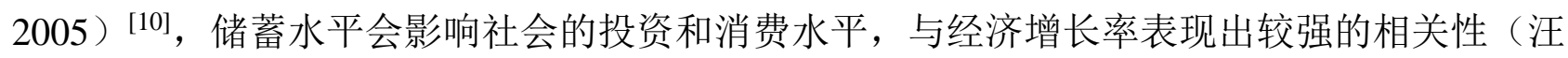
伟，2008） [11]，因此在控制变量中本文以地区居民储蓄规模来度量地区的储蓄水平对经济增 长的作用。 
表 1 主要变量及其计算方式

\begin{tabular}{|c|c|c|c|}
\hline 变量类型 & 变量名称 & 变量含义 & 计算方法 \\
\hline 被解释变量 & $G D P$ & 地区经济增长水平 & $\begin{array}{c}\text { 以地区实际人均 } G D P \text { 增长率来衡量地区经 } \\
\text { 济增长水平 }\end{array}$ \\
\hline 核心解释变量 & $G T D$ & 国家体育产业基地 & 虚拟变量 $(0,1)$ \\
\hline \multirow[t]{5}{*}{ 控制变量 } & GOV & 政府规模 & $\begin{array}{c}\text { 用地方政府预算内支出除以地区生产总值 } \\
\text { 表示 }\end{array}$ \\
\hline & $F D I$ & 外商直接投资水平 & $\begin{array}{c}\text { 地区实际利用外商直接投资除以地区生产 } \\
\text { 总值 }\end{array}$ \\
\hline & $F A R$ & 固定资产投资水平 & $\begin{array}{c}\text { 用每年固定资产投资额除以地区生产总值 } \\
\text { 来表示 }\end{array}$ \\
\hline & $E D U$ & 教育水平 & $\begin{array}{c}\text { 用地区普通高等学校在校生数除以总人口 } \\
\text { 表示 }\end{array}$ \\
\hline & $S A V$ & 储蓄规模 & $\begin{array}{c}\text { 以地区居民储蓄除以地区生产总值来度量 } \\
\text { 地区的储蓄水平 }\end{array}$ \\
\hline
\end{tabular}

\section{3 数据来源与描述性统计}

本文利用所选取 15 个样本地区 2000-2015 年的面板数据进行实证研究, 数据主要来源于 国家统计局、国研网统计数据库和国家体育总局, 各变量的描述性统计见表 2 。

表 2 主要变量的描述性统计

\begin{tabular}{|c|l|l|l|l|}
\hline 变量含义 & \multicolumn{1}{|c|}{ 标准误 } & \multicolumn{1}{|c|}{ 均值 } & \multicolumn{1}{|c|}{ 极小值 } & \multicolumn{1}{|c|}{ 极大值 } \\
\hline 地区经济增长水平 & 0.1402 & 0.0566 & 0.0037 & 0.2906 \\
\hline 国家体育产业基地 & 0.2777 & 0.4491 & 0 & 1 \\
\hline 政府规模 & 0.1107 & 0.0439 & 0.0392 & 0.2870 \\
\hline 外商直接投资水平 & 0.0436 & 0.0341 & 0.0034 & 0.2864 \\
\hline 固定资产投资水平 & 0.5004 & 0.2233 & 0.0986 & 1.1398 \\
\hline 教育水平 & 0.0426 & 0.0329 & 0.0036 & 0.1270 \\
\hline 储蓄规模 & 0.6815 & 0.2776 & 0.1358 & 1.6063 \\
\hline
\end{tabular}

\section{4 估计方法与模型构建}

为了检验设立国家体育产业基地对地区经济增长的作用, 可以通过比较地区经济增长在 设立基地之前和设立了基地之后的差异，以此来判断该项政策对经济增长的作用（单差法）。 但这种单差法得出的结论可能是不准确的, 因为在基地设立的前后, 还有很多其他因素会影 响地区经济增长。此外, 同一时期出台的其他政策也可能使得那些未设立基地的城市获得发 展, 这些因素无疑都会对地区经济增长产生重要的作用, 并最终影响评价结果。而运用单差 法时不能将这种差异考虑在内, 从而可能高估国家体育产业基地建设对经济增长的作用, 因 此运用双重差分方法来评价国家体育产业基地对地区经济增长的作用在更为科学一些。

在本文的 15 个地区样本中, 截止到 2015 年有 6 个地区先后获批建设国家级体育产业基 地, 这为我们提供了一个良好的“准自然实验”来采用双重差分方法。具体来说, 在我们的样 本中, 这 6 个地区就构成了处理组, 其余构成对照组。根据地方获批建设国家级体育产业基 地的时间, 我们设置 $G T D$ 变量, 地区在获批前 $G T D=0$, 之后 $G T D=1$ 。这样我们可以构造以 下双向固定效应计量模型来实现双重差分, 检验高新技术产业开发区对地区经济增长的净效 应:

$$
Y_{i t}=\beta_{0}+\beta_{1} G T D+\alpha X_{i t}+\gamma_{t}+\mu_{i}+\varepsilon_{i t}
$$

其中, $Y_{i t}$ 为被解释变量, 本文选取了 $G D P$ 增长率来衡量国家级体育产业基地的设立对地 区经济增长的作用, 下标 $i$ 和 $t$ 分别表示第个 $i$ 地区和第 $t$ 年, $\gamma_{t}$ 代表时间固定效应, $\mu_{i}$ 代表各 
地级市的个体固定效应。 $X_{i t}$ 为其他控制变量, 包括地区固定资产投资水平、外商直接投资水 平、政府规模、地区人口受教育水平和地区储蓄水平等。对于上述模型, 系数 $\beta_{1}$ 的估计值是 我们关注的重点, 它度量了国家级体育产业基地的设立对地区经济增长的净影响。如果这一 经济政策确实推动了地区经济增长，那么 $\beta_{1}$ 的系数应该显著为正。

\section{4. 实证结果与分析}

\section{1 国家级体育产业基地对地区经济增长的影响}

本文首先估计国家级体育产业基地对地区经济增长的直接影响。由于体育产业基地的设 立在全国的地级市中表现出差异化特征，为我们提供了一个“准自然实验”，因此本文运用双 重差分方法来评估国家级体育产业基地的设立对地区经济增长的净效应，回归结果反映在表 3 。在表 3 中, 第 1 列是没有加入其他控制变量时的估计结果, 第 2 列是加入其他控制变量的 结果。可以发现, 无论是否加入其他控制变量, 本文重点关注的 GTD 的回归系数均显著为正, 这表明建设国家级体育产业基地对地区经济增长有着显著的推动作用。

表 3 国家体育产业基地的设立对地区经济增长的作用

\begin{tabular}{|c|c|c|}
\hline 被解释变量 & $G D P$ & $G D P$ \\
\hline 解释变量 & $(1)$ & $(2)$ \\
\hline$G T D$ & $0.1824^{* * *}$ & $0.1813^{* * *}$ \\
\hline & $(0.001)$ & $(0.003)$ \\
\hline$G O V$ & & $0.1646^{* * *}$ \\
\hline & & $(0.007)$ \\
\hline$F D I$ & & $0.2153^{* *}$ \\
\hline$F A R$ & & $(0.036)$ \\
\hline$E D U$ & & $0.3248^{* * *}$ \\
\hline & & $(0.006)$ \\
\hline$S A V$ & & -0.003 \\
\hline & & $(0.189)$ \\
\hline$R^{2}$ & 0.846 & $0.1548^{* *}$ \\
\hline & & $(0.0270)$ \\
\hline
\end{tabular}

注：（1）括号里为 $\mathrm{P}$ 值; (2) *、**、***分别表示在 $10 \% 、 5 \%$ 和 $1 \%$ 的水平下显著。

\section{2 稳健性检验}

为了检验结果的稳健性, 我们借鉴已有研究 (陈刚, 2012; 范子英、田涁涁, 2013) [12]-[13], 通过改变政策执行时间进行反事实检验。除了国家体育产业基地设立这一政策变化外，一些 其他政策或随机性因素也可能导致地区经济增长产生差异，而这种差异与产业基地的设立没 有关联, 最终导致前文的结论不成立。为了排除掉这类因素的影响, 我们假定各地区设立国 家体育产业基地的年份统一提前 2 年或 3 年，如果此时国家体育产业基地的变量变得显著为 正，则说明经济增长很可能来自于其他政策变革或者随机性因素，而不是国家体育产业基地 的设立。如果此时变量并不显著为正，则说明经济增长的增量贡献来自于国家体育产业基地 的设立。表 4 中第 1 列表示假想国家体育产业基地的设立时间提前两年的情况，第 2 列表示 假想国家体育产业基地设立时间提前 3 年的情况。各项检验表明，假想的基地设立时间并不 显著，这从另一方面表明国家体育产业基地的设立可以促进当地经济的发展。 
表 4 国家体育产业基地推动经济增长: 反事实检验

\begin{tabular}{|c|c|c|}
\hline 被解释变量 & $G D P$ & $G D P$ \\
\hline 解释变量 & $(1)$ & $(2)$ \\
\hline$G T D$ & 0.1341 & 0.1298 \\
\hline & $(0.386)$ & $(0.547)$ \\
\hline$G O V$ & $0.1446^{* * *}$ & $0.1546^{* * *}$ \\
\hline & $(0.002)$ & $0.004)$ \\
\hline$F D I$ & $0.2014^{* *}$ & $(0.014)$ \\
\hline$F A R$ & $(0.016)$ & $0.3414^{* * *}$ \\
\hline & $0.3308^{* * *}$ & $(0.005)$ \\
\hline$E D U$ & $(0.003)$ & 0.0213 \\
\hline$S A V$ & 0.0176 & $(0.268)$ \\
\hline & $(0.245)$ & $0.1264^{* * *}$ \\
\hline$R^{2}$ & $0.1346^{* *}$ & $(0.0167)$ \\
\hline & $(0.0180)$ & 0.936 \\
\hline
\end{tabular}

注：（1）括号里为 P 值; （2）*、**、***分别表示在 $10 \% 、 5 \%$ 和 $1 \%$ 的水平下显著。

\section{3 进一步的检验: 边际效应递减规律的验证}

根据假说 2, 初始的资源要素水平和经济增长程度差异会导致国家体育产业基地的设立 对地区经济增长的作用不尽相同，产业基地对地区经济增长的推动作用是边际递减的，因此 初始条件越好的地区从中获得的收益将低于相对落后的地区。为了验证该理论, 选取发达城 市和欠发达城市两个分类指标，构建如下回归方程，以检验假说 2 是否成立。

$$
Y_{i t}=\beta_{0}+\beta_{1} \text { citylevel }^{*} G T D+\alpha X_{i t}+\gamma_{t}+\mu_{i}+\varepsilon_{i t}
$$

其中, citylevel代表城市等级，在不同的方程中，分别代表发达城市（fadacity）、欠发 达城市（unfadacity）。其他符号的含义和方程（1）中相同。交互项系数 $\beta_{1}$ 度量在不同类别的 城市设立体育产业基地对地区经济增长的作用，如果假说 2 中的边际效应递减规律成立，那 么 $\beta_{1}$ 的估计值应该会随着城市发展水平的上升呈现递减的趋势。相关计量结果呈现在表 5 中。

表 5 国家体育产业基地推动经济增长的进一步验证

\begin{tabular}{|c|c|c|}
\hline 被解释变量 & $G D P$ & $G D P$ \\
\hline 解释变量 & $(1)$ & $(2)$ \\
\hline fadacity* $G T D^{*}$ & $0.1034^{* * *}$ & \\
\hline unfadacity* $G T D$ & $(0.005)$ & $0.2343^{* * *}$ \\
\hline & & $(0.002)$ \\
\hline$G O V$ & $0.1663^{* * *}$ & $0.1542^{* * *}$ \\
\hline & $(0.006)$ & $(0.004)$ \\
\hline$F D I$ & $0.2104^{* *}$ & $0.2032^{* *}$ \\
\hline$F A R$ & $(0.012)$ & $(0.015)$ \\
\hline & $0.3102^{* * *}$ & $0.3018^{* * *}$ \\
\hline$E D U$ & $(0.007)$ & $0.004)$ \\
\hline & 0.0206 & 0.0196 \\
\hline$S A V$ & $(0.285)$ & $(0.315)$ \\
\hline$R^{2}$ & $0.1536^{* *}$ & $0.1472^{* *}$ \\
\hline & $(0.0162)$ & $(0.0156)$ \\
\hline & 0.914 & 0.956 \\
\hline
\end{tabular}

注：（1）括号里为 P 值; (2) * ***、***分别表示在 $10 \%$ 、5\%和 $1 \%$ 的水平下显著。

观察表 5 可以发现，发达城市的交互项为正但不显著，而且系数较小; 欠发达城市的交 
互项显著为正，且系数大于发达城市交互项; 这表明国家体育产业基地的设立对地区经济增 长的推动作用呈现逐级递减的规律。也即, 产业基地对于经济增长的推动作用随着城市等级 和初始禀赋条件的上升而下降，呈现出“边际效应递减”规律。这一发现意味着，体育产业基 地的设立不仅可以推动地区经济增长, 而且如果能够合理布局也可以帮助缩小地区经济增长 的差异。

\section{5. 结论和政策启示}

在当前经济进入新常态的背景下，挖掘新的经济增长点具有重要意义，经过长达 10 多年 的探索，国家体育产业基地的发展模式以日趋成熟，为各地具有一定体育产业基础的城市经 济增长提供了一个重要参考。同时, 如何准确地认知和评价产业基地对地区经济增长的作用 也是人们关注的重点问题。本文首次利用中国 15 个地区 2000-2015 年的面板数据, 采用双重 差分方法对国家体育产业基地是否推动地区经济增长这一问题进行了验证。研究表明, 国家 体育产业基地的设立可以显著地提升地区的经济增长水平，这一结果在进行稳健性检验后仍 然成立。而且, 产业基地的经济推动作用呈现出“边际效应递减”的规律, 在那些发达、要素 资源更具优势的地区，产业基地对地区经济增长的作用要更低。这一发现表明，如果能够合 理布局, 国家体育产业基地的设立在推动整体经济增长的同时, 还可以缩小发达地区和落后 地区之间的经济增长差距。

就当前的中国现实来看，虽然各个地区均在改革开放的政策下取得了一定的发展，但是 依然存在部分地区发展速度缓慢、地区差距日趋严重的难题。国家体育产业基地作为国家的 一项重要的“政策实验”，无疑为解决这些难题提供了一个政策方向。一方面，有鉴于国家体 育产业基地对于地区经济增长的积极作用，我们应当充分利用好这一政策，依据各地的基础 条件和产业优势不断推进体育基地的建设, 以推动本地区经济的增长。另一方面, 落后地区 由于初始的经济条件较差, 经济增长的提升空间很大, 争取获批设立国家体育产业基地也会 给本地区提供了一次发展的机遇, 可以从这项政策中获得更快速的经济增长, 以缩小与发达 地区经济增长的差距。因此, 国家应该从整体发展战略出发, 充分意识到基地建设对于地区 经济增长的拉动作用, 合理规划国家体育产业基地的布局, 实现向那些欠发达的地区倾斜, 这将有利于在保持整体经济不断提升的同时兼顾地区间的平衡发展。

\section{References}

[1] Mato B. Evaluation of the economic impact of sport in developed countries and Croatia.[J]. Kinesiology, 1997.

[2] Zhao Nie,Undertakings of physical culture and sports and study on the relationship between the economic and social development in henan[J].HENAN SOCIAL SCIENCES,2009,(03):210-211.

[3] Chen Wensheng,Contribution to the economic development of our country sports industry development of the empirical analysis[J].CONTEMPOARY SPORTS TECHNOLOGY,2012(19):72-73+75

[4] XUE Liang, Co-integrative Analysis between Sports Industry and Economic Development in China[J].JOURNAL OF CHANGSHA UNIVERSITY OF SCIENCE \& TECHNOLOGY(SOCIAL SCIENCE), 2017,(03):110-116.

[5] LIN Xiang-yang,ZHOU Hong-mei, Construction of national level sports industry base[J]. Journal of Wuhan Institute of Physical Education, 2008,(08):45-48+70.

[6] LIANG Qiang,Research on the Construction Path and Promoting Strategies of the National Sports Industry Base[J].Journal of Hebei Institute of physical Education, 2013,(03):1-4. 
[7] XING Zun-ming,CHENG Yi-hui,HU Wei;MENG Qing-guang,CHEN Hong-miao, National Sports Industry Base:Implementing Process, Characteristic Analysis,Promotion Strategy[J].CHINA SPORT S CIENCE, 2014,(01):66-74.

[8] Lin Yifu, Liu Peilin, Chinese Development Strategy and Economic Convergence[J]. Economic research, 2003,(03):19-25+89.

[9] Li Guoping ,Fan Hongzhong, The Distribution of Production ,Population and Regional Inequality[J]. Economic research, 2003,(11):79-86+93.

[10]Li Yang, Yin Jianfeng, High Saving Rate , High Investment Rate and Chinese Economic Growth During Labour Transition[J]. Economic research, 2005,(02):4-15+25.

[11]Wang Wei, The Studies on the Dynamic Relationship among Savings, Investment and Economic Growth-Empirical Research of China from 1952 to 2006[J],NANKAI ECONOMIC STUDIES,. 2008,(02):105-125.

[12]Chen Gan,Li Shu, Judicial Independence and Market Fragmentation-Evidence from the Geographical R otation of Judges in China[J].Economic research, 2013,(09):30-42+70.

[13]Fan Ziying,Tian Binbin, Tax Competition, Tax Enforcement and Tax Avoidance[J]. Economic research, 2013,(09):99-111. 